\title{
Impacts of VR 3D sketching on novice designers' spatial cognition in collaborative conceptual architectural design
}

\begin{abstract}
Conventional Computer Aided Design tools lack intuitivity for being used in conceptual architectural design process. This paper identifies the impact of using a haptic based VR 3D sketching interface for integrating novice designersôcognitions and actions to improve design creativity. This study employs protocol analysis for comparing the collective cognitive and collaborative design protocols of three pairs of novice architectural designers in both 3D and manual sketching sessions. Results show that the simple and tangible haptic based design interface improved designersô cognitive and collaborative activities. These improvements also increased their engagement with óproblem-spaceôand ôsolution-spaceôthat led towards more artefact maturity. Research findings from this study can help the development of cutting-edge haptic-based collaborative virtual environments in architectural education and associated professions.
\end{abstract}

Keyword: Architectural design; Design cognition; Virtual reality; Protocol analysis; Collaborative design 